\title{
Mode of administration of dulaglutide: implications for treatment adherence
}

\author{
This article was published in the following Dove Press journal: \\ Patient Preference and Adherence \\ 2 June 2016 \\ Number of times this article has been viewed
}

\author{
Ambika Amblee ${ }^{1,2}$ \\ 'Department of Internal Medicine, \\ Division of Endocrinology, John \\ Stroger Hospital of Cook County, \\ ${ }^{2}$ Rush University Medical Center, \\ Chicago, IL, USA
}

Background: Medication complexity/burden can be associated with nonadherence in patients with type 2 diabetes mellitus (T2DM). Patients' satisfaction with their treatment is an important consideration for physicians. Strategies like using longer acting efficacious agents with less frequent dosing may help adherence.

Objective: To explore the mode of administration of dulaglutide and its implications for treatment adherence in T2DM.

Methods: PubMed search using the term "Dulaglutide" through October 31, 2015 was conducted. Published articles, press releases, and abstracts presented at national/international meetings were considered.

Results/conclusion: Dulaglutide is a once-weekly glucagon like peptide-1 analog with a low intraindividual variability. Phase III trials demonstrated significant improvements in glycemia and weight, with a low hypoglycemia risk similar to liraglutide/exenatide, but with substantially fewer injections. A significant improvement was observed in the total Diabetes Treatment Satisfaction Questionnaire score, Impact of Weight on Self-Perception, and perceived frequency of hyperglycemia with dulaglutide when compared with placebo, exenatide, liraglutide, or metformin. Treatment satisfaction scores showed an improvement with dulaglutide (34\%-39\%) when compared with exenatide (31\%). A positive experience with a high initial $(97.2 \%)$ and final (99.1\%) injection success rate along with a significant reduction in patients' fear of selfinjecting, as measured by the modified self-injecting subscale of the Diabetes Fear of Injecting and Self-Testing Questionnaire and Medication Delivery Device Assessment Battery, was found. Its acceptance was high $(>96 \%)$ among a variety of patients including patients who fear injections and injection-naïve users. Dulaglutide is available as a single-dose automatic self-injecting device, which has a low volume, does not need reconstitution, and avoids patient handling of the needle. Dose adjustment based on weight, sex, age, race, ethnicity, or injectionsite is not necessary. In chronic diseases like diabetes where patients need lifelong medications, the efficacy, safety, and convenience of a once-weekly, easy-to-use, self-injecting device should encourage patient adherence to dulaglutide therapy.

Keywords: type 2 diabetes, weekly GLP1, treatment satisfaction, quality of life, patient treatment satisfaction

\section{Introduction}

Glucagon like peptide-1 (GLP-1) analogs are a growing class of novel therapeutic agents that provide glucose-dependent insulin secretion and decrease in glucagonemia, leading to better blood glucose control. ${ }^{1}$ GLP-1 agonists have additional effects such as delaying gastric emptying and increasing satiety, which lead to weight reduction. ${ }^{1}$ The first GLP-1 agonist approved for the treatment of type 2 diabetes mellitus (T2DM) was exenatide in 2005, followed by liraglutide. The efficacy and weight loss potential 
of the various GLP-1 agonists vary, and hemoglobin A1c ( $\mathrm{HbA} 1 \mathrm{c}$ ) reduction can range from $0.8 \%$ for Byetta to $\sim 1 \%$ for extended-release exanetide, dulaglutide, and albiglutide. ${ }^{2}$

In the recent 2012 position statement from the American Diabetes Association and the European Association for the Study of Diabetes, GLP-1 analogs are among several classes of antidiabetic agents recommended for second- or third-line therapy. ${ }^{3}$ In these guidelines, individualization of diabetes therapy based on the patient's comorbid conditions is recommended. In patients who are obese or overweight, GLP-1 analogs were one of the options recommended as second-line therapy to help with weight loss. ${ }^{3}$ In the 2015 guidelines from the American Diabetes Association, the indications have broadened and suggest that GLP-1 analogs can be used in patients on triple therapy with poor glycemic control, and as an alternative to mealtime insulin. ${ }^{4}$ The American Association of Clinical Endocrinologists guidelines even suggest using GLP-1 analogs as monotherapy when metformin is contraindicated or not tolerated. ${ }^{5}$

Patient adherence to therapy, defined as taking medications as prescribed, is important in controlling diabetes progression and preventing long-term complications. Medication adherence is associated with reduced disease morbidity in chronic cardiovascular $(\mathrm{CV})$ disease $^{6}$ and reduced health care resource utilization. ${ }^{7}$ In a systematic review of diabetes treatment adherence, it was shown that better adherence was found to be associated with improved glycemic control and decreased health care resource utilization. ${ }^{8}$ An adherence rate of $80 \%$ or greater was associated with significant decreases in total medical costs for diabetes, hypertension, and hypercholesterolemia. ${ }^{7}$

In chronic diseases like diabetes where patients need to take lifelong medications, it is important to develop strategies to improve adherence like using patient-friendly, longer-acting efficacious agents with less frequent dosing. The frequency of dosing for GLP-1 analogs has improved from twice daily to once daily and now once weekly. Newer, once-weekly GLP-1 analogs like dulaglutide (approved in 2014) are now available which, in addition to glycemic control and weight loss benefits, may simplify therapy and improve patient adherence.

\section{Review of pharmacology, mode of action, and pharmacokinetics of dulaglutide Pharmacology and mode of action}

Dulaglutide is a GLP-1 analog, which has a long half-life and can be dosed weekly. The principle behind the creation of dulaglutide is that fusing GLP-1 to a larger carrier molecule will slow its clearance and prolong its half-life. ${ }^{9}$ The free dipeptidyl peptidase-4-protected dulaglutide was covalently linked to a modified Fc fragment of human immunoglobulin (IgG) $4 .{ }^{10}$ This resulting dulaglutide molecule had a flat profile with no burst activity, and had fourfold greater potency in vitro when compared with the free dipeptidyl peptidase4-protected GLP-1, which made it suitable for once-weekly dosing. ${ }^{10}$ The modified IgG4 molecule reduced interactions with high-affinity Fc receptors, eliminated half-antibody formation, and reduced cell-mediated cytotoxicity, thus reducing the immunogenic potential. ${ }^{10}$

\section{Pharmacokinetics}

\section{Animal studies}

In vitro assessments in isolated rat and cynomolgus monkey islet cells showed that a concentration of $300 \mathrm{nM}$ of dulaglutide was needed to produce a fourfold increase in insulin secretion, like native human GLP-1. ${ }^{10}$ An in vivo study in cynomolgus monkeys showed that serum levels of dulaglutide and C-peptide levels were detectable for 7 days after a single subcutaneous injection of dulaglutide $(1.7 \mathrm{nmol} / \mathrm{kg})$.

\section{Human studies}

In a Phase I study, 20 healthy adult subjects, 19-52 years of age, underwent a three-period, double-blind, placebo-controlled crossover study, where various doses of dulaglutide $(0.1$, $0.3,1,3,6$, and $12 \mathrm{mg}$ ) were tested. ${ }^{11}$ The maximum dulaglutide concentration occurred between 24 and 48 hours after dosing with a mean half-life of $\sim 3.75$ days ( 89.9 h) with an intrasubject coefficient of variation of $18.7 \%$. The various doses of dulaglutide showed a dose-dependent decrease in glucose, and increase in insulin concentrations. A delay in gastric emptying was seen with 1 and $3 \mathrm{mg}$ dulaglutide doses given weekly for 4 weeks in 30 healthy volunteers, only after the first dose, and not in the steady state. ${ }^{12}$

A Phase Ib multicenter, placebo-controlled, double-blind study assessed the safety and tolerability of six different subcutaneous doses of dulaglutide $(0.05,0.3,1,3,5$, and $8 \mathrm{mg})$ given weekly for 5 weeks. ${ }^{13}$ The study enrolled 43 patients with T2DM between ages of 38 and 65 years, who were on diet and exercise only or on one oral diabetes medication. Results showed that steady state concentration levels were obtained after the second weekly dose. ${ }^{13}$ The time to maximal drug concentration ranged from 12 to 72 hours. ${ }^{13}$ The mean plasma half-life determined after the last dose was 95.4 hours. ${ }^{13}$ Intrasubject variability for area under the curve for dulaglutide was $14.6 \%$, and intersubject variability was $30.8 \% .{ }^{13}$ A significant reduction in fasting plasma glucose 
(FPG) and $\mathrm{HbAlc}$ was seen in all the dulaglutide doses except the $0.3 \mathrm{mg}$ dose. Dulaglutide doses $>1 \mathrm{mg}$ also showed a significant reduction in 2 hours postprandial plasma glucose (PPPG).

A Phase II, 12-week study assessed the safety and efficacy of four doses of dulaglutide $(0.1,0.5,1.0$, and $1.5 \mathrm{mg})$ in 167 patients with T2DM with mean age of 56.6 years, who were treatment-naïve or on metformin monotherapy. ${ }^{14}$ A dose-dependent decrease was noted in mean $\mathrm{HbA1c}$, preprandial plasma glucose and PPPG levels in the dulaglutide $0.5,1.0$, and $1.5 \mathrm{mg}$ groups compared with the placebo group. The percentages of patients achieving an $\mathrm{HbAlc}$ goal of $<7 \%$ and $\leq 6.5 \%$ were higher in the dulaglutide groups compared with placebo. ${ }^{14}$ At week 12, there was a statistically significant increase in the homeostasis model assessment of $\beta$-cell function in all dulaglutide groups except the $0.1 \mathrm{mg}$ group. ${ }^{14}$

Another study was a 16-week, placebo-controlled, double-blind study, which enrolled 262 adult patients with T2DM on two oral antidiabetic medications with mean age of $57 \pm 12$ years, body mass index $33.9+4.1 \mathrm{~kg} / \mathrm{m}^{2}$ and $\mathrm{HbA} 1 \mathrm{c}$ of $8.24 \%+0.93 \% .^{15}$ Multiple doses of dulaglutide, both titrated and fixed, were tested; dulaglutide $0.5 \mathrm{mg}$ weekly for 4 weeks followed by $1.0 \mathrm{mg}$ for 12 weeks (dulaglutide $0.5 / 1.0 \mathrm{mg}$ ) versus $1 \mathrm{mg}$ for 16 weeks (dulaglutide $1.0 / 1.0 \mathrm{mg}$ ) versus $1 \mathrm{mg}$ weekly for 4 weeks and then $2 \mathrm{mg}$ weekly for 12 weeks (dulaglutide $1.0 / 2.0 \mathrm{mg}$ ). The placebo-adjusted mean $\mathrm{HbAlc}$ decrease seen at the end of the study was statistically significant for all dulaglutide groups with about $49 \%-54 \%$ achieving an $\mathrm{HbA} 1 \mathrm{c}$ level of $<7 \%$ and $29 \%-32 \%$ achieving an HbAlc $\leq 6.5 \% .{ }^{15}$ FPG also reduced significantly in all three dulaglutide groups, ranging from 37 to $48 \mathrm{mg} / \mathrm{dL}(2.05-2.65 \mathrm{mmol} / \mathrm{L})$ compared with placebo. ${ }^{15}$ There was significant weight loss $(1.34-2.55 \mathrm{~kg})$ in all the three dulaglutide dose groups along with an improvement in homeostasis model assessment of $\beta$-cell function. ${ }^{15}$

The Assessment of Weekly Administration of LY2189265 (dulaglutide) in Diabetes (AWARD)-5, a double-blind study of patients with T2DM, included a dose-finding section where patients were randomized 3:1:1 to seven dulaglutide doses ranging from 0.25 to $3.0 \mathrm{mg} .{ }^{16}$ Dulaglutide $1.5 \mathrm{mg}$ was determined to be the optimal dose and dulaglutide $0.75 \mathrm{mg}$ as the second best dose based on a clinical utility index. ${ }^{16}$

Thus, the pharmacokinetics of dulaglutide allow for onceweekly administration in patients with T2DM. ${ }^{17}$ There was no difference in pharmacokinetics between injection sites (arm, thigh, or abdomen) ${ }^{17}$ Age, body weight, sex, race, and ethnicity did not influence dulaglutide pharmacokinetics to any clinically relevant degree and thus dose adjustment is not necessary on the basis of these features. ${ }^{17}$ Dulaglutide has not been studied in patients with end-stage renal disease. No dose adjustments are needed in patients with mild-to-moderate renal impairment. ${ }^{18}$

\section{Overview of the various modes of administration of dulaglutide}

Dulaglutide is administered subcutaneously, once weekly, into the abdomen, thigh, or upper arm, at any time of day, without regard to meals. It was approved in 2014 in two dose strengths, 0.75 and $1.5 \mathrm{mg} .{ }^{18,19}$ The volume of both doses is $0.5 \mathrm{~mL}$ and it comes as a single-dose pen or prefilled syringe. Both forms are disposable and are supplied with a needle attached. It does not require reconstitution, and there is no need to dial the dose. ${ }^{18,19}$ The prefilled subcutaneous automatic injection device extends a needle, delivers dulaglutide, and retracts the needle with the push of a button, without patients having to handle the needle..$^{18,19}$ The pen should be stored in the refrigerator $\left(36^{\circ} \mathrm{F}-46^{\circ} \mathrm{F}, 2^{\circ} \mathrm{C}-8^{\circ} \mathrm{C}\right)$, but can be stored at room temperature for up to 14 days. ${ }^{18}$ The initial starting dose is $0.75 \mathrm{mg}$ once weekly and can be increased to $1.5 \mathrm{mg}$ once weekly if additional glycemic control is needed. ${ }^{18}$ Missed doses should be administered within 3 days of the missed dose. ${ }^{18}$

\section{Potential effects of the mode of administration of dulaglutide on treatment adherence}

Administration of dulaglutide can lead to sustained glycemic control, and early achievement of glycemic goals may encourage adherence to dulaglutide. The effectiveness and safety of dulaglutide was shown in multiple Phase III randomized controlled trials; the AWARD studies (Table 1). ${ }^{20-25}$ The various trials were conducted over a period of 26-104 weeks on patients with T2DM on dual and triple therapy. The reduction in $\mathrm{HbAlc}$ was better with dulaglutide $1.5 \mathrm{mg}$ than with exenatide, metformin, or sitagliptin, and was noninferior to liraglutide (Table 1). ${ }^{20-25}$ Changes in other glycemic parameters, weight changes, and other details are shown in Table 1.

It is common for patients to hesitate to start insulin for various reasons including inconvenience of daily injections. Dulaglutide 1.5 and $0.75 \mathrm{mg}$ were compared with insulin glargine in two studies, AWARD-2 and AWARD-4 (Table 1) ${ }^{22,23}$ Statistical criteria for superiority were met with dulaglutide $1.5 \mathrm{mg}$ and for noninferiority with dulaglutide $0.75 \mathrm{mg} .{ }^{22,23}$ More patients on dulaglutide $1.5 \mathrm{mg}$ achieved HbA1c targets $<7.0 \%(53 \mathrm{mmol} / \mathrm{mol})$ versus glargine $(P<0.001) .{ }^{22,23}$ Body weight decreased with dulaglutide 


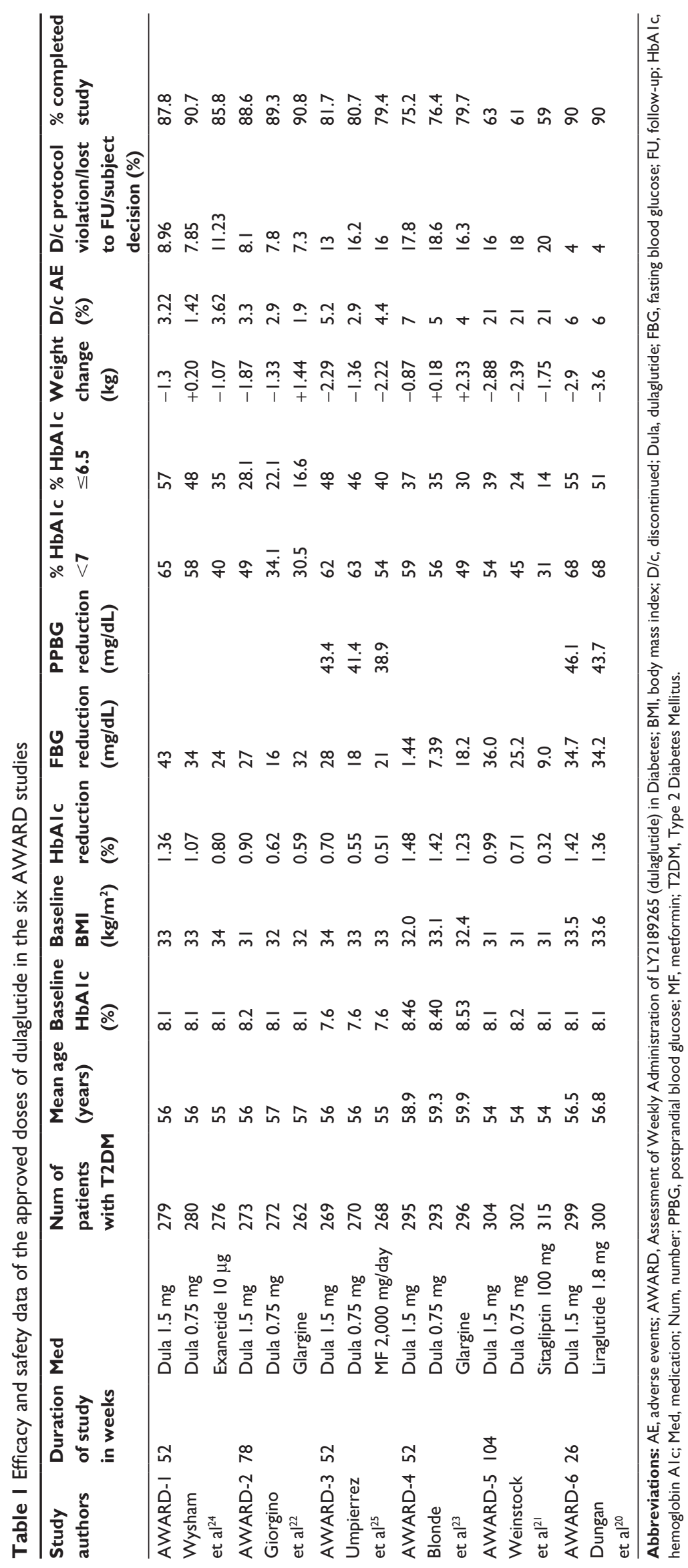


and increased with glargine..$^{22,23}$ Total hypoglycemia rates were lower with dulaglutide; severe hypoglycemia was minimal. ${ }^{22}$ Once-weekly dulaglutide $1.5 \mathrm{mg}$ demonstrated greater $\mathrm{HbAl} \mathrm{c}$ reduction and weight loss compared with daily insulin glargine without forced titration. There was a higher incidence of adverse gastrointestinal events with dulaglutide, but a lower risk of hypoglycemia and a lower injection frequency ${ }^{22}$ Dulaglutide in combination with lispro resulted in a significantly greater improvement in glycemic control versus a combination of glargine and lispro, and represents a new treatment option for patients unable to achieve glycemic targets with conventional insulin treatment. ${ }^{23}$

A Phase III, nonrandomized, open-label, parallel-group, 52-week study enrolled 394 Japanese patients with T2DM, with mean age of 57.4 years, who were on various single oral agents, to assess the safety and efficacy of once-weekly dulaglutide $0.75 \mathrm{mg} .{ }^{26}$ Dulaglutide was well tolerated with $92.9 \%$ completing the 52-week treatment period. ${ }^{26}$ The hypoglycemia incidence varied across the combination therapy groups, with a greater incidence seen in patients receiving sulfonylurea compared with other oral agents. ${ }^{26}$ No severe hypoglycemic episodes occurred during the study. ${ }^{26}$ Significant $\mathrm{HbA} 1 \mathrm{c}$ reduction ranging from $-1.57 \%$ to $-1.69 \%$ was seen in all combination therapy groups. ${ }^{26}$ The mean body weight changes from baseline showed wide variation and depended on the oral agent patients were on. ${ }^{26} \mathrm{~A}$ significant increase in weight was seen with the dulaglutide/thiazolidinedione combination, no significant weight changes in combination with sulfonylureas or glinides, and weight loss was seen in combination with biguanides and $\alpha$-glucosidase inhibitors. ${ }^{26}$ Overall, once-weekly dulaglutide $0.75 \mathrm{mg}$ in combination with a single oral agent was well tolerated and improved glycemic control in Japanese patients with T2DM. ${ }^{26}$

Post hoc analyses were done on AWARD-1 to AWARD-6, randomized controlled trials that evaluated dulaglutide 0.75 and $1.5 \mathrm{mg}$ with active comparators and placebo with the composite end point of $\mathrm{HbAlc}$, weight, and hypoglycemia. ${ }^{27}$ A total of 4,287 patients with T2DM (1,424 on dulaglutide $1.5 \mathrm{mg}$ and 1,124 on dulaglutide $0.75 \mathrm{mg}$ ), with a mean age ranging from 54.1 to 56.7 years, were enrolled in the five trials. At 26 weeks, within each study, $37 \%-58 \%$ of patients on dulaglutide $1.5 \mathrm{mg}, 27 \%-49 \%$ of patients on dulaglutide $0.75 \mathrm{mg}$, and $9 \%-61 \%$ on active comparators achieved the composite end point. ${ }^{27}$ Dulaglutide 1.5 and $0.75 \mathrm{mg}$ groups had significantly more patients who reached the composite end point when compared with metformin, sitagliptin, exenatide, and insulin glargine. However, there was no difference between dulaglutide $1.5 \mathrm{mg}$ and liraglutide $1.8 \mathrm{mg}{ }^{27}$
Since the short-acting GLP-1 delayed gastric emptying, it had greater effects on PPPG levels, whereas the longeracting compounds like dulaglutide reduced plasma glucose throughout the 24-hour period studied..$^{28}$ Post hoc analyses of AWARD-5 and AWARD-1 showed a strong association between FPG $<142 \mathrm{mg} / \mathrm{dL}(7.9 \mathrm{mmol} / \mathrm{L})$ at week 2 and achieving the $\mathrm{HbAlc}$ efficacy end point at week $26 .{ }^{28} \mathrm{FPG}$ measured at 2 weeks may be an early and useful predictor of glycemic response to once-weekly dulaglutide treatment. ${ }^{28}$ The incidence of hypoglycemia and injection site reactions were low with dulaglutide $1.5 \mathrm{mg} .{ }^{20}$ More patients treated with dulaglutide achieved $\mathrm{HbAl} 1 \mathrm{c}$ targets of $<7 \%$ and $\leq 6.5 \%$ with infrequent hypoglycemia. Reduction in weight was greater with dulaglutide than with sitagliptin and exenatide. ${ }^{29}$

The effects of the dulaglutide 0.75 and $1.5 \mathrm{mg}$ doses on blood pressure and heart rate using ambulatory blood pressure monitoring were tested in 755 patients with T2DM, with ages ranging from 46 to 67 years, and who were on $\geq 1$ oral diabetes medication for 26 weeks. ${ }^{30}$ Dulaglutide $1.5 \mathrm{mg}$ significantly reduced systolic blood pressure $(-2.8 \mathrm{mmHg})$ with both dulaglutide doses being noninferior to placebo for changes in 24-hour systolic and diastolic blood pressure. ${ }^{30}$ Dulaglutide $0.75 \mathrm{mg}$ was noninferior to placebo for changes in mean 24-hour heart rate from baseline at 16 and 26 weeks, while dulaglutide $1.5 \mathrm{mg}$ showed a least squares mean increase in heart rate of 3 to 4 beats per minute versus placebo. ${ }^{30}$

A recent meta-analysis of nine randomized trials involving 6,010 patients $(3,885$ on dulaglutide and 2,125 on comparator therapy or placebo) with a cumulative exposure to either dulaglutide or comparator therapy of 3,941 and 2,223 patient-years, respectively, evaluated CV risk in these patients. ${ }^{31}$ The primary outcome, a four-component major adverse CV event was found in $0.67 \%$ in the dulaglutide group versus $1.18 \%$ in the comparator group (hazard ratio 0.57 ; adjusted $98.02 \% \mathrm{CI}$ of $0.30,1.10$ ) indicating that dulaglutide does not increase the risk of major adverse $\mathrm{CV}$ events in patients with T2DM. ${ }^{31}$

A validated simulation research model (IMS CORE Diabetes Model) was used to estimate expected costs and outcomes in Sweden of liraglutide $1.8 \mathrm{mg}$ versus dulaglutide $1.5 \mathrm{mg}$ from the AWARD-6 trial and from a network metaanalysis comparing dulaglutide $1.5 \mathrm{mg}$ versus liraglutide $1.2 \mathrm{mg}{ }^{32}$ This included Swedish-specific direct and indirect costs over a lifetime time horizon. ${ }^{32}$ One-way sensitivity and probabilistic sensitivity analysis demonstrated that dulaglutide $1.5 \mathrm{mg}$ was dominant over liraglutide $1.8 \mathrm{mg}$ given plausible variations in key input parameters. ${ }^{32}$ The model 
found that dulaglutide $1.5 \mathrm{mg}$ was more effective and less costly than either liraglutide 1.2 or $1.8 \mathrm{mg}$ for the treatment of T2DM in the Swedish setting. ${ }^{32}$

Thus, Phase III trials from the AWARD program demonstrated significant improvements in $\mathrm{HbA} 1 \mathrm{c}$ and weight, and a low hypoglycemia risk with dulaglutide 0.75 or $1.5 \mathrm{mg}$ weekly. ${ }^{29,20-25}$ The efficacy, safety, low incidence of hypoglycemia, and the convenience of a once-weekly injection with an easy-to-use, self-injecting device may encourage patients to be more compliant with dulaglutide therapy. In fact, a compliance of $\geq 75 \%$ was found in a mean of $96.7 \%-99.5 \%$ of patients per treatment group in one study. ${ }^{15}$

\section{Patient-focused perspectives such as quality of life and patient satisfaction/acceptability}

Medication complexity and burden has been shown to be associated with medication nonadherence in T2DM. ${ }^{33}$ It has also been shown that people with T2DM are more likely to adhere to treatments if they are satisfied with them ${ }^{34}$ and that certain variables like administration of multiple injections, interference of daily activities as a result of injection regimens, and injection pain and embarrassment are associated with poor medication adherence. ${ }^{35}$ Hence, a patient's perception of their condition and its associated treatment is an important consideration for physicians when making treatment decisions, and can be used to assess whether improvements in clinical variables are associated with psychosocial harm or benefit. ${ }^{36}$ These outcome measures have been studied in various trials.

To compare treatment satisfaction among people with T2DM receiving dulaglutide $1.5 \mathrm{mg}$ and dulaglutide $0.75 \mathrm{mg}$, the Diabetes Treatment Satisfaction Questionnaire status version (DTSQs) and change version were used. The total treatment satisfaction and perceived frequency of hyperglycemia and hypoglycemia were evaluated in the AWARD-1 and AWARD-3 studies. ${ }^{36}$ In addition, a few other measures like weight-related self-perception as measured by Impact of Weight on Self-Perception (IW-SP), Ability to Perform Physical Activities of Daily Living Questionnaire, perceived current health status as measured by EuroQoL 5-Dimension Questionnaire (EQ-5D) and diabetes symptoms (Diabetes Symptom Checklist-Revised) were also tested at baseline, 26 and 52 weeks in AWARD-3.36,37

In AWARD-1, the total DTSQs score improved from baseline for both dulaglutide doses (26 and 52 weeks) and was significantly greater when compared with placebo (26 weeks) and exenatide (26 and 52 weeks). ${ }^{36}$ This showed that patients were more satisfied with dulaglutide than their previous therapies at 52 weeks. ${ }^{36}$ In AWARD-3, the scores for DTSQs and IW-SP improved significantly in all groups at 26 and 52 weeks, while no significant changes were observed in any group in the scores for Ability to Perform Physical Activities of Daily Living Questionnaire, Diabetes Symptom Checklist-Revised, and EQ-5D. ${ }^{36}$ Another measure used to assess treatment satisfaction was the minimally important changes in DTSQs total treatment satisfaction scores using distribution-based approaches. ${ }^{36}$ There was an improvement as shown in AWARD-1 and AWARD-3 for both dulaglutide 1.5 and $0.75 \mathrm{mg}$ groups $(34 \%-39 \%)$ when compared with exenatide group (31\%). ${ }^{36}$ In AWARD-1, the perceived frequency of hyperglycemia was lower for both the dulaglutide groups, while the perceived frequency of hypoglycemia was higher for the exenatide group at 26 and 52 weeks. In AWARD-3, the perceived frequency of hyperglycemia was also lower in the metformin group at 26 and 52 weeks. ${ }^{36}$ However, this improvement was greater with both dulaglutide doses compared with metformin at 52 weeks. ${ }^{36}$ EQ-5D visual analog scale score showed significant improvements for both dulaglutide dose groups and exenatide at 26 and 52 weeks. ${ }^{37}$ The conclusion from both studies was that dulaglutide was associated with improvements in treatment satisfaction and a decrease in perceived frequency of hyperglycemia. ${ }^{36}$

AWARD-2 and AWARD-4, where dulaglutide was compared with insulin Lantus and Humalog, also assessed certain patient satisfaction questionnaires like EQ-5D, IW-SP, and perceived frequency of hypoglycemia. ${ }^{38,39}$ The results are yet to be reported. In AWARD-6, the 299 patients randomized to dulaglutide $1.5 \mathrm{mg}$ used prefilled syringes and when compared with liraglutide, showed significant improvements in IW-SP, the ED-5Q (visual analog scale), the ability to perform physical activities of daily living, and the ED-5Q dimensions UK population score. ${ }^{20}$

A 4-week, Phase IIIb, multicenter, open-label, single-arm, outpatient study evaluated the use of the dulaglutide singledose pen containing $0.5 \mathrm{~mL}$ of placebo for subcutaneous injection in 211 injection-naïve adult patients with T2DM with $\mathrm{HbA} 1 \mathrm{c} \leq 8.5 \%(69 \mathrm{mmol} / \mathrm{mol})$ and body mass index between 23 and $45 \mathrm{~kg} / \mathrm{m}^{2}{ }^{40}$ Patients completed a modified self-injecting subscale of the Diabetes Fear of Injecting and Self-Testing Questionnaire (mD-FISQ) and were trained to self-inject with the single-dose pen. Patients completed the initial self-injection at the clinical site, injected at home for 2 subsequent weeks, and returned to the site for the final injection. ${ }^{40}$ Patients recorded their level of pain after each injection. After the final injection, patients completed the mD-FISQ and the Medication Delivery Device Assessment Battery to assess their perceptions of the single-dose pen, including ease of use and experience with the device. ${ }^{40}$ The initial injection success 
rate was $97.2 \%$, while the final self-injection success rate was $99.1 \% .^{40}$ More than $96 \%$ found the device easy to use, were satisfied with the device, and would be willing to continue to use the single-dose pen after the study. There was a significant reduction $(P<0.001)$ from baseline in patients' fear of selfinjecting, as measured by the mD-FISQ. ${ }^{40}$ The dulaglutide single-dose pen was found to be a safe and effective device for use by patients with T2DM who were injection-naïve. A positive injection experience is an important factor for patients and physician providers when initiating injectable therapy. ${ }^{40}$

Similar data for the prefilled syringe is not available. However among the six AWARD studies, AWARD-5 and AWARD-6 clearly state that dulaglutide was administered using prefilled syringes, and data for efficacy and safety are available..$^{20,21}$ Patient satisfaction, acceptance, and adherence can also be inferred from the percentage who completed the studies as shown in Table 1. Except for AWARD-5, in which $61 \%-63 \%$ of patients completed the study, the completion rates for the other five studies were very high, ranging from $75.2 \%$ to $90.8 \% .^{20,22-25}$

\section{Conclusion}

Dulaglutide is one of the five GLP-1 analogs approved for T2DM in the US. Dulaglutide targets multiple pathophysiological mechanisms in patients with T2DM, improves glycemic control, and may be an appropriate treatment for patients with T2DM. It is an effective option because it is dosed once-weekly, provides $\mathrm{HbA} 1 \mathrm{c}$ reduction similar to liraglutide, weight reduction similar to exenatide, and has an adverse effect profile similar to other GLP-1 analogs. Dulaglutide weekly is recommended as an add-on agent to existing metformin monotherapy, especially when weight loss is required, and as first-line therapy if metformin is contraindicated or poorly tolerated. It can also be used in combination with other oral glucose-lowering agents or basal insulin. Dulaglutide has been shown to be noninferior to once-daily liraglutide. This may help with decision-making and individualizing treatment for patients with T2DM, since patients administer substantially fewer injections with dulaglutide yet achieve similar glycemic benefits. ${ }^{20}$ Long-term, once-weekly dulaglutide may improve compliance compared with more frequently administered regimens including multiple insulin injection therapy. ${ }^{20} \mathrm{~A}$ recent meta-analysis showed that dulaglutide was not associated with an increase in $\mathrm{CV}$ events. ${ }^{28}$ However, data to assess $\mathrm{CV}$ risk and long-term safety are still needed.

Administration of dulaglutide is user-friendly, has a low injection volume $(0.5 \mathrm{~mL})$, and comes as a single-dose pen or prefilled syringe with a needle already attached. It does not need reconstitution, unlike other weekly GLP-1 analogs.
The device can be used by a wide variety of patients, including those who fear injections, since it uses an automatic injection mechanism that will extend a needle, deliver dulaglutide, and retract the needle with the push of a button, eliminating the need for patient handling of the needle. Dosage errors can also be avoided as there is no need to dial a dose with the dulaglutide injections.

In chronic diseases like diabetes where patients need to take lifelong medications, it is important to develop strategies to improve adherence. One such strategy is to use longeracting, safer, efficacious agents with less frequent dosing. Newer, once-weekly dulaglutide may simplify therapy and improve patient adherence.

\section{Disclosure}

The author reports no conflicts of interest in this work.

\section{References}

1. Drucker DJ, Nauck MA. The incretin system: glucagon-like peptide-1 receptor agonists and dipeptidyl peptidase- 4 inhibitors in type 2 diabetes. Lancet. 2006;368:1696-1705.

2. Karagiannis T, Liakos A, Bekiari E, et al. Efficacy and safety of onceweekly glucagon-like peptide 1 receptor agonists for the management of type 2 diabetes: a systematic review and meta-analysis of randomized controlled trials. Diabetes Obes Metab. 2015;17(11):1065-1074.

3. Inzucchi SE, Bergenstal RM, Buse JB, et al. American Diabetes Association (ADA); European Association for the Study of Diabetes (EASD). Management of hyperglycemia in type 2 diabetes: a patient-centered approach: position statement of the American Diabetes Association (ADA) and the European Association for the Study of Diabetes (EASD). Diabetes Care. 2012;35(6):1364-1379.

4. Inzucchi SE, Bergenstal RM, Buse JB, et al. Management of hyperglycemia in type 2 diabetes, 2015: a patient-centered approach: update to a position statement of the American Diabetes Association and the European Association for the Study of Diabetes. Diabetes Care. 2015;38: 140-149.

5. Garber AJ, Abrahamson MJ, Barzilay JI, et al. AACE comprehensive diabetes management algorithm 2013. Endocr Pract. 2013;19: 327-336.

6. Albert NM. Improving medication adherence in chronic cardiovascular disease. Crit Care Nurse. 2008;28(5):54-64.

7. Sokol MC, McGuigan KA, Verbrugge RR, Epstein RS. Impact of medication adherence on hospitalization risk and health care cost. Med Care. 2005;43(6):521-530.

8. Asche C, LaFleur J, Conner C. A review of diabetes treatment adherence and the association with clinical and economic outcomes. Clin Ther. 2011;33(1):74-109.

9. Picha KM, Cunningham MR, Drucker DJ, et al. Protein engineering strategies for sustained glucagon-like peptide-1 receptor-dependent control of glucose homeostasis. Diabetes. 2008;57(7):1926-1934.

10. Glaesner W, Vick AM, Millican R, et al. Engineering and characterization of the long-acting glucagon-like peptide-1 analogue LY2189265, an Fc fusion protein. Diabetes Metab Res Rev. 2010;26(4):287-296.

11. Barrington P, Chien JY, Tibaldi F, Showalter HD, Schneck K, Ellis B. LY2189265, a long-acting glucagon-like peptide-1 analogue, showed a dose-dependent effect on insulin secretion in healthy subjects. Diabetes Obes Metab. 2011;13:434-438.

12. Chien JY, Cui S, Chaudhary A, Loghin C. LY2189265, a long-acting glucagon-like peptide-1 analog does not affect gastric emptying of acetaminophen after multiple dosing in healthy subjects. Diabetes. 2010;59:Suppl 1:Abs 600-P. 
13. Barrington P, Chien JY, Showalter HD, et al. A 5-week study of the pharmacokinetics and pharmacodynamics of LY2189265, a novel, long-acting glucagon-like peptide-1 analogue, in patients with type 2 diabetes. Diabetes Obes Metab. 2011;13(5):426-433.

14. Grunberger G, Chang A, Garcia Soria G, Botros FT, Bsharat R, Milicevic Z. Monotherapy with the once-weekly GLP-1 analogue dula for 12 weeks in patients with type 2 diabetes: dose-dependent effects on glycemic control in a randomized, double-blind, placebo-controlled study. Diabet Med. 2012;29(10):1260-1267.

15. Umpierrez GE, Blevins T, Rosenstock J, et al; EGO Study Group. The effects of LY2189265, a long-acting glucagon-like peptide-1 analogue, in a randomized, placebo-controlled, double-blind study of overweight/ obese patients with type 2 diabetes: the EGO study. Diabetes Obes Metab. 2011;13(5):418-425.

16. Skrivanek Z, Gaydos BL, Chien JY, et al. Dose-finding results in an adaptive, seamless, randomized trial of once-weekly dulaglutide combined with metformin in type 2 diabetes patients (AWARD-5). Diabetes Obes Metab. 2014;16(8):748-756.

17. Geiser JS, Heathman MA, Cui X, et al. Clinical pharmacokinetics of dulaglutide in patients with type 2 diabetes: Analyses of data from clinical trials. Clin Pharmacokinet. 2016;55(5):625-634.

18. Trulicity (dulaglutide) product information. Available from: http://uspl. lilly.com/trulicity/trulicity.html\#pi. Accessed December 10, 2015.

19. Trulicity (dulaglutide) instructions for use. Available from: http://uspl. lilly.com/trulicity/trulicity.html\#ug. Accessed December 10, 2015.

20. Dungan KM, Povedano ST, Forst T, et al. Once-weekly dulaglutide versus once-daily liraglutide in metformin-treated patients with type 2 diabetes (AWARD-6): a randomised, open-label, phase 3, non-inferiority trial. Lancet. 2014;384(9951):1349-1357.

21. Weinstock RS, Guerci B, Umpierrez G, Nauck MA, Skrivanek Z, Milicevic Z. Safety and efficacy of once-weekly dulaglutide versus sitagliptin after 2 years in metformin-treated patients with type 2 diabetes (AWARD-5): a randomized, phase III study. Diabetes Obes Metab. 2015;17(9):849-858.

22. Giorgino F, Benroubi M, Sun JH, Zimmermann AG, Pechtner V. Efficacy and safety of once-weekly dulaglutide versus insulin glargine in patients with type 2 diabetes on metformin and glimepiride (AWARD-2). Diabetes Care. 2015;38(12):2241-2249.

23. Blonde L, Jendle J, Gross J, et al. Once-weekly dulaglutide versus bedtime insulin glargine, both in combination with prandial insulin lispro, in patients with type 2 diabetes (AWARD-4): a randomised, open-label, phase 3, non-inferiority study. Lancet. 2015;385:2057-2066.

24. Wysham C, Blevins T, Arakaki R, et al. Efficacy and safety of dulaglutide added onto pioglitazone and metformin versus exenatide in type 2 diabetes in a randomized controlled trial (AWARD-1). Diabetes Care. 2014;37(8):2159-2167.

25. Umpierrez G, Tofé Povedano S, Pérez Manghi F, Shurzinske L, Pechtner V. Efficacy and safety of dulaglutide monotherapy versus metformin in type 2 diabetes in a randomized controlled trial (AWARD-3). Diabetes Care. 2014;37(8):2168-2176.

26. Emoto M, Terauchi Y, Ozeki A, Oura T, Takeuchi M, Imaoka T. A 1-year safety study of dulaglutide in Japanese patients with type 2 diabetes on a single oral hypoglycemic agent: an open-label, nonrandomized, phase 3 trial. Endocr J. 2015;62(12):1101-1114.
27. Dungan KM, Raz I, Skrivanek Z, Sealls W, Fahrbach JL. Achieving the composite endpoint of $\mathrm{HbAlc}<7.0 \%$, no weight gain, and no hypoglycaemia in the once weekly dulaglutide AWARD program. Diabetes Obes Metab. 2016;18(1):49-55.

28. Grunberger G, Forst T, Fernández Landó L, et al. Early fasting glucose measurements can predict later glycemic response to once weekly dulaglutide. Diabet Med. 2016;33(3):391-394.

29. Gurung T, Shyangdan DS, O'Hare JP, Waugh N. A novel, long-acting glucagon-like peptide receptor-agonist: dulaglutide. Diabetes Metab Syndr Obes. 2015;8:363-386.

30. Ferdinand KC, White WB, Calhoun DA, et al. Effects of the onceweekly glucagon-like peptide-1 receptor agonist dulaglutide on ambulatory blood pressure and heart rate in patients with type 2 diabetes mellitus. Hypertension. 2014;64(4):731-737.

31. Ferdinand KC, Botros FT, Atisso CM, Sager PT. Cardiovascular safety for once-weekly dulaglutide in type 2 diabetes: a pre-specified metaanalysis of prospectively adjudicated cardiovascular events. Cardiovasc Diabetol. 2016;15:38.

32. Raibouaa A, Borgeke H, Alexiou D, Lowin J, Norrbacka K. Costeffectiveness of dulaglutide $1.5 \mathrm{mg}$ once weekly for the treatment of patients with type two diabetes mellitus in Sweden. Value Health. 2015; 18(7):A607.

33. Ingersoll KS, Cohen J. The impact of medication regimen factors on adherence to chronic treatment: a review of literature. J Behav Med.2008; 31:213-224

34. Davies M, Speight J. Patient-reported outcomes in trials of incretinbased therapies in patients with type 2 diabetes mellitus. Diabetes Obes Metab. 2012;14:882-892.

35. Peyrot M, Rubin RR, Kruger DF, Travis LB. Correlates of insulin injection omission. Diabetes Care. 2010;33:240-245.

36. Reaney M, Yu M, Lakshmanan M, Pechtner V, van Brunt K. Treatment satisfaction in people with type 2 diabetes mellitus treated with onceweekly dulaglutide: data from the AWARD-1 and AWARD-3 clinical trials. Diabetes Obes Metab. 2015;17(9):896-903.

37. Van Brunt K, Reaney M, Yu M, Lakshmanan M, Curtis B, Mitchell B. Patient-reported outcomes with dula, exenatide, or placebo (AWARD-1). In: Proceedings of the 49th European Association for the Study of Diabetes (EASD) Annual Meeting; 2013; Barcelona, Spain. Abstract 985.

38. A Randomized, open-label, parallel-arm, noninferiority comparison of the effects of two doses of LY2189265 and insulin glargine on glycemic control in patients with type 2 diabetes on stable doses of metformin and glimepiride (AWARD-2). Available from: ClinicalTrails.gov. ClinicalTrials.gov Identifier: NCT01075282. Accessed November 20, 2015.

39. The impact of LY2189265 versus insulin glargine in combination with insulin lispro for the treatment to target of type 2 diabetes mellitus (AWARD-4: Assessment of Weekly AdministRation of LY2189265 in Diabetes-4). Available from: ClinicalTrails.gov. ClinicalTrials.gov Identifier: NCT01191268. Accessed November 20, 2015.

40. Matfin G, Van Brunt K, Zimmermann AG, Threlkeld R, Ignaut DA. Safe and effective use of the once weekly dulaglutide single-dose pen in injection-naïve patients with type 2 diabetes. J Diabetes Sci Technol. 2015;9(5):1071-1079.
Patient Preference and Adherence

\section{Publish your work in this journal}

Patient Preference and Adherence is an international, peer-reviewed, open access journal that focuses on the growing importance of patient preference and adherence throughout the therapeutic continuum. Patient satisfaction, acceptability, quality of life, compliance, persistence and their role in developing new therapeutic modalities and compounds to optimize

\section{Dovepress}

clinical outcomes for existing disease states are major areas of interest for the journal. This journal has been accepted for indexing on PubMed Central. The manuscript management system is completely online and includes a very quick and fair peer-review system, which is all easy to use. Visit http://www. dovepress.com/testimonials.php to read real quotes from published authors. 